\title{
FOCAL ACHALASIA - CASE REPORT AND REVIEW OF THE LITERATURE
}

\author{
MARCUS JOACHIM HERZIG ${ }^{1}$, RADU TUTUIAN ${ }^{2}$
}

\author{
${ }^{1}$ Magen-Darmpraxis Münsingen, Inselgruppe, Switzerland \\ ${ }^{2}$ Gastroenterology Department, Tiefenauspital, Inselgruppe, Bern, Switzerland
}

\begin{abstract}
Esophageal achalasia is a primary smooth muscle motility disorder specified by aperistalsis of the tubular esophagus in combination with a poorly relaxing and occasionally hypertensive lower esophageal sphincter (LES). These changes occur secondary to the destruction of the neural network coordinating esophageal peristalsis and LES relaxation (plexus myentericus). There are limited data on segmental involvement of the esophagus in adults.

We report on the case of a 54-year-old man who presented initially with complete aperistalsis limited to the distal esophagus. After a primary good response to BoTox-infiltration of the distal esophagus the patient relapsed two years later. The manometric recordings documented now a progression of the disease with a poorly relaxing hypertensive lower esophageal sphincter and complete aperistalsis of the tubular esophagus (type III achalasia according to the Chicago 3.0 classification system).

This paper also reviews diagnostic findings (including high resolution manometry, CT scan, barium esophagram, upper endoscopy and upper endoscopic ultrasound data) in patients with achalasia and summarizes the therapeutic options (including pneumatic balloon dilatation, botulinum toxin injection, surgical or endoscopic myotomy).
\end{abstract}

Keywords: esophageal achalasia, high resolution esophageal manometry, dysphagia, esophageal sphincter lower dilatation, esophageal motility disorders

\section{Introduction}

Achalasia is a rare motor disorder of the esophagus that typically presents with slowly progressive dysphagia for solids and liquids and frequently regurgitations (5-7). Chest pain, weight loss, nocturnal cough, aspiration and pneumonia are less typical symptoms. This disease is characterized by esophageal aperistalsis and insufficient relaxation of the lower esophageal sphincter caused by degeneration of the myenteric plexus. The etiology remains poorly understood and a multifactorial origin is suspected.

In 1674 Sir Thomas Williams was the first to report on a disease characterized by food blockage in the esophagus of unknown origin. The proposed treatment

Manuscript received: 28.07.2017

Accepted: 30.08 .2017

Address for correspondence: mjuherzig@hotmail.com was, as it is today, a dilatation of the lower esophageal sphincter (LES). In the 17th century the "gold standard" for treating achalasia was a device consisting of a whale bone in combination with a sponge [1]. In $1927 \mathrm{Sir}$ Arthur Hurst coined the current name of this disease - based on the Greek terms of "a" = missing and "chalasis" = relaxation - describing the lack of relaxation / opening of the lower esophageal sphincter [2].

While the idiopathic form is the most common form of achalasia, 2-4\% of patients with suspected achalasia are found to have pseudoachalasia or Chagas disease. In these subgroups a degeneration of the myenteric plexus is due to neoplastic infiltration [3] or infection with Trypanosoma cruzi [4].

We report a case of a patient presenting with dysphagia who initially displayed a focal form of achalasia 
in the distal esophagus that evolved over time to a more typical picture of achalasia. We consider the case interesting as we had the chance to capture the findings of an early form of achalasia and were able to document the progression to what is now classified as Type III achalasia according to the Chicago 3.0 criteria.

Furthermore, the current manuscript summarizes aspects of epidemiology, pathophysiology, diagnostic modalities, treatment options and prognosis plus follow-up of achalasia.

\section{Case Report}

A 54-year old male was referred to our clinic for the evaluation of a 2 years history of intermittent progressive dysphagia for solids and liquids. He reported dysphagia for solids with the sensation of food getting stuck in the mid esophagus and regurgitation when drinking rapidly on several occasions on 3-4 days per week. He denied chest pain, heartburn or weight loss.

The patient's past medical history included surgery for a herniated disc L5/S1 more than 20 years ago with reoperation 3 years later and treatment with isoretinoin 10 years ago for acne. A trial of PPI therapy for one month did not relieve symptoms. At the time of the consultation he had not taken any medications.

Prior to being referred to our clinic the patient underwent an upper gastrointestinal endoscopy, with unremarkable findings both macroscopic and on esophageal biopsies. A barium esophagogram revealed a delayed passage of contrast media to the stomach and a dilated distal esophagus with an irregularity in the esophago-gastric junction (EGJ) (Figure 1). Due to this irregularity of the EGJ he underwent an endoscopic ultrasound (EUS) exam of the esophagus that revealed a thickened lower esophageal sphincter with small calcifications of the mucosa and no evidence of malignoma or extrinsic compression of the esophagus.

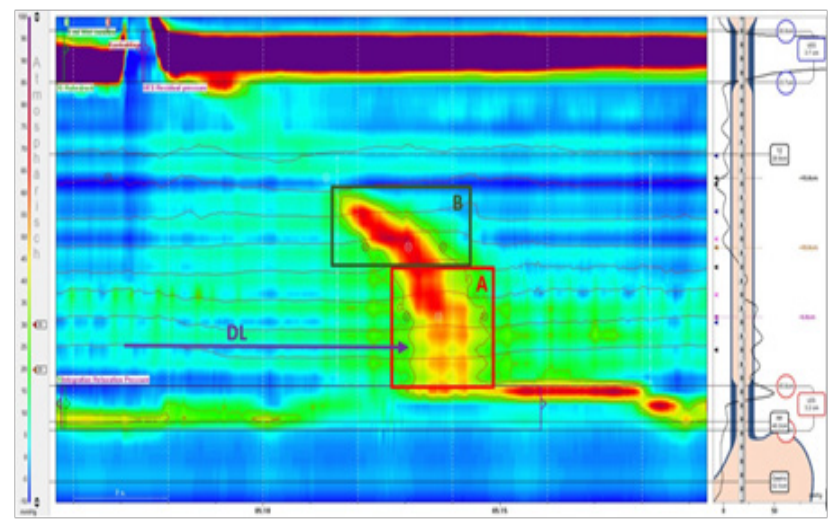

Figure 1. Initial barium esophagram: Bird beaks appearance and irregularity of the EGJ, dilated distal esophagus.
The next diagnostic step was a high-resolution esophageal manometry (HRM) which revealed a lower esophageal sphincter resting pressure just above the upper limit of normal (average LES-resting pressure 46mmHg; normal $10-45 \mathrm{mmHg}$ ) with inadequate relaxation characterized by an elevated integrated relaxation pressure (IRP4s) (average $20.2 \mathrm{mmHg}$; normal $<15 \mathrm{mmHg}$ ). In addition, the contraction pattern of the tubular esophagus found a segmental aperistalsis in the distal esophoagus from $6 \mathrm{~cm}$ above to the LES with a normal distal latency (DL) (average DL $5.85 \mathrm{~s}$; normal $>4.5 \mathrm{~s}$ ). The HRM contraction patterns are depicted in Figure 2.

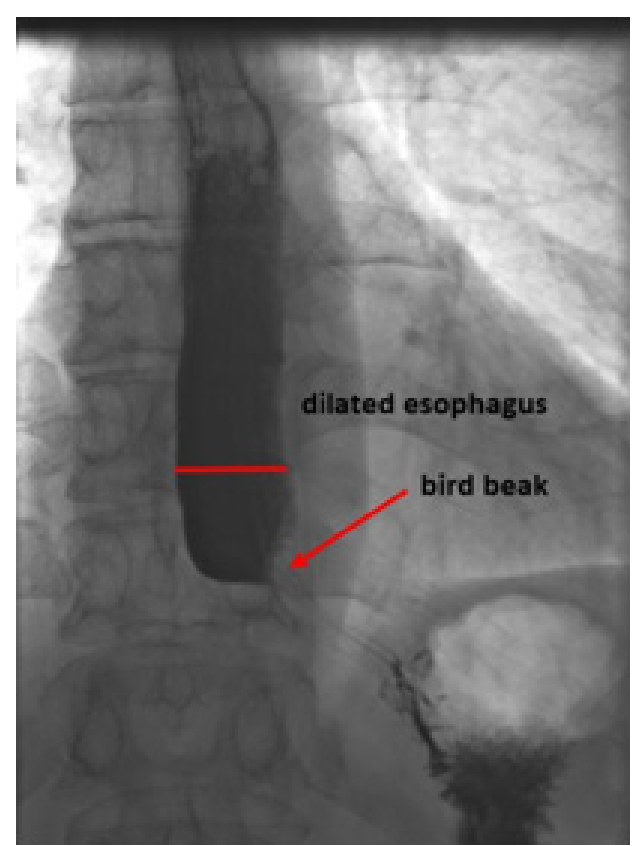

Figure 2. Initial high resolution esophageal manometry image documenting segmental aperistalsis (A) in the distal esophagus from about $6 \mathrm{~cm}$ above the LES, normal propagation of the peristaltic wave (B) with a normal distal latency (DL) of $5.85 \mathrm{~s}$ (normative $>4.5 \mathrm{~s}$ ) and a poorly relaxing lower esophageal sphincter (LES) defined by an integrated relaxation pressure (IRP4s) of $20.2 \mathrm{mmHg}$ (normative $<17 \mathrm{mmHg}$ in achalasia type III) and a residual pressure of $21 \mathrm{mmHg}$ (normative $<8 \mathrm{mmHg}$ ) with a slightly elevated resting pressure of $46 \mathrm{mmHg}$ (normative $10-45 \mathrm{mmHg}$ ).

We interpreted the segmental aperistalsis of the distal esophagus associated with the inadequate relaxation of the hypertensive LES and the radiologic findings as an incomplete resp. early form of "segmental" achalasia but, given the calcifications in a thickened LES, we included in the differential diagnosis the possibility of secondary outflow obstruction due to a peptic stenosis. Consequently, we offered the patient the option of a dilatation with Savary bougies 15-18 mm, which was accepted and performed. This intervention improved the symptoms only for a few 
days, and at the follow-up visit 4 weeks after the Savary dilatation he continued to report dysphagia for solids and liquids, thoracic pain twice a month and regurgitation monthly.

The symptoms slowly progressed and further therapeutic options were discussed with the patient along the concept of a focal form of achalasia. As he was concerned of the risks of pneumatic dilatation (PD), per oral endoscopic myotomy (POEM) and surgery, he decided for botulinum toxin injections, 25IE botulinum toxin to each quadrant of the LES. A few days after the intervention the patient reported a complete resolution of his symptoms. The highresolution esophageal manometry measurements 6 weeks after BoTox injection found a near normal relaxation of the LES but still simultaneous contractions from the mid to the distal esophagus with a normal DL (Figure 3).

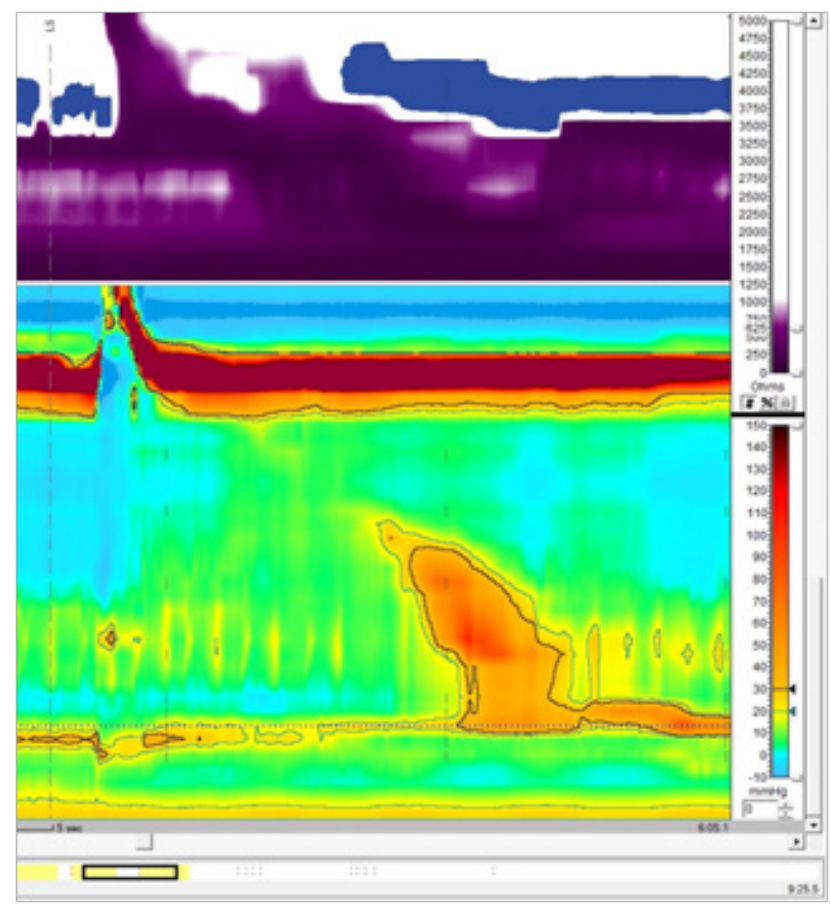

Figure 3. High resolution esophageal manometry following botulinum toxin injection to the LES recording documenting segmental aperistalsis in the distal esophagus, normal propagation of the peristaltic wave with a normal distal latency (DL) (normative $>4.5 \mathrm{~s}$ ) and a near normal relaxing lower esophageal sphincter (LES) defined by a residual pressure of $9.1 \mathrm{mmHg}$ (normative $<8 \mathrm{mmHg}$ ) with a normal resting pressure of $24.8 \mathrm{mmHg}$ (normative $10-45 \mathrm{mmHg}$ ).

Twenty-two months later the patient presented back with dysphagia, thoracic pain and regurgitation, but no weight loss. This time, the HRiM revealed an insufficient relaxation of the LES (residual pressure $22 \mathrm{mmHg}$, IRP4s $21.4 \mathrm{mmHg}$ ) and complete aperistalsis indicated by simultaneous contractions of the whole esophagus. The criteria proposed by the Chicago classification for achalasia type III were met (Figure 4). The barium esophagram showed a similar picture as the previous examination, with narrowing of the EGJ and a dilated esophagus (Figure 5). The patient was still worried about the risks of pneumatic balloon dilatation, POEM and surgery and, given the good initial response, he opted for repeated botulinum toxin injection, which led to a complete remission of esophageal symptoms for one year. As symptoms recurred, the patient agreed for a pneumatic balloon dilatation with $30 \mathrm{~mm}$ balloon and remained free of dysphagia until present.

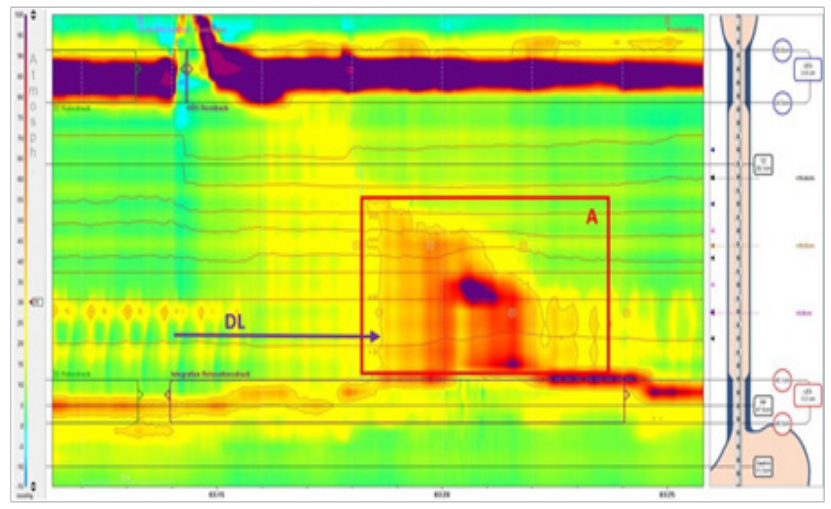

Figure 4. High resolution esophageal manometry 4 years after initial examination. Aperistalsis of the whole esophageal body (A). Distal latency $4.6 \mathrm{~s}$ (DL) (normative $>4.5 \mathrm{~s}$ ). Poorly relaxing LES defined by an IRP4s of $21.4 \mathrm{mmHg}$ (normative $<17 \mathrm{mmHg}$ in achalasia type III) and residual pressure of $8 \mathrm{mmHg}$ (normative $<8 \mathrm{mmHg}$ ). LES at the upper border of normal with $43 \mathrm{mmHg}$ (normative 10-45 $\mathrm{mmHg}$ ).

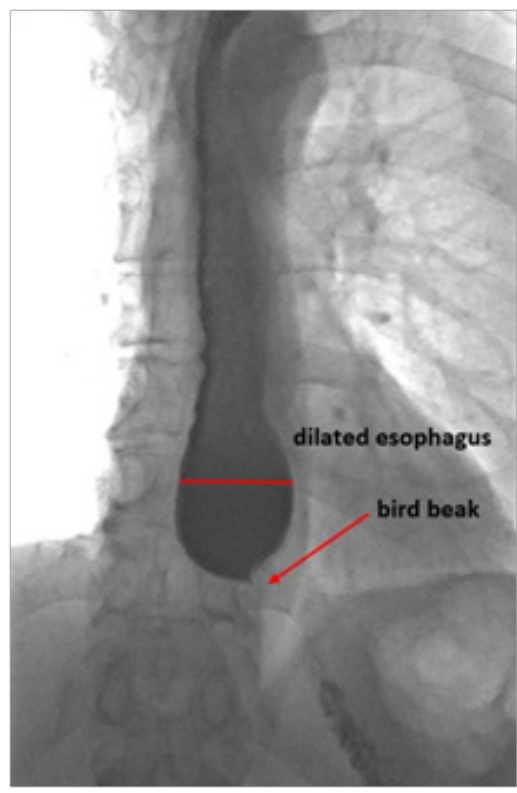

Figure 5. Barium esophagram 4 years after initial presentation. 


\section{Discussion and review of the literature}

The reported worldwide annual incidence of achalasia is approximately $1 / 100000(5-7)$. The incidence rates vary in the reported studies according to geographic locations, between 0.03/100 000 in Zimbabwean native population [5], $0.55 / 100000$ in Iceland [6] and 1.63/100 000 in a Canadian population [7]. The prevalence varies between 1.8/100 000 in Singapore [8] and 13.4/100 000 in Ireland [9].

There are no particular age or gender differences among patients with achalasia compared to the general population. Achalasia affects males and females equally $[6,7]$, although slightly higher rates in females have been reported. Non-Caucasian and Caucasian are affected in the same proportion $[9,10]$. A bimodal distribution of incidence by age has been suggested with peaks around 30 and 60 years [11,12], while other investigations indicated a rising risk of achalasia with increasing age [13,14].

Primary achalasia is related to an inflammatory degeneration of the inhibitory ganglion cells of the esophagus myenteric plexus and the LES resulting in a loss of inhibitory neurons [15]. This degeneration results in a defective relaxation of the LES and abnormal peristaltic contractions of the esophagus. Although achalasia is described for more than 300 years, little is known yet about etiology of this disease. Investigations support a multifactorial origin of achalasia including infectious agents, autoimmune responses and genetic factors as potential triggers.

As Chagas' disease exhibits similar features to achalasia [16], an infectious etiology has been widely debated although the evidence remains contradictory. A possible involvement of Herpes simplex virus (HSV) type 1 was suspected given the immune response cells in the region of the LES $[17,18]$, although no relationship of an active or latent viral infection with HSV, HPV or measles was proved in other studies $[19,20]$.

Booy et al. found that patients with achalasia are compared to the general population 3.6 times more prone to suffer from any autoimmune condition (relative risk 5.4 for type I diabetes mellitus, 8.5 for hypothyroidism, 37 for Sjögren's syndrome, 43 for systemic lupus erythematosus, 259 for uveitis) [20]. Another study detected an overall higher prevalence of neural autoantibodies in patients with achalasia compared to a healthy control group [21]. Though no specific autoantibody was identified so far, these data support the hypothesis that achalasia has an autoimmune component.

In a study reviewing the incidence of achalasia in New Zealand a difference in between the ethnic groups of the Pacific Islanders (1.3/100 000) and the Maori (0.2/100 000 ) was evident (23). Therefore, geographic factors may be of minor significance.

Twin and sibling studies and the association of achalasia with other diseases such as Parkinson disease, Allgrove and Down syndrome may also reflect a possible genetic background for this disease, hence no specific mutations could be identified up to present $[22,23,24,25]$.
The hallmark symptom associated with achalasia is slowly progressive dysphagia for both solids and liquids and is seen in $79 \%-100 \%$ of affected patients. Other common symptoms are regurgitation (63\%), heartburn (41\%), non-cardiac chest pain (22\%), epigastric pain (15\%) and odynophagia $(<5 \%)$. In patients with achalasia, respiratory symptoms are also common: cough (37\%), aspiration (31\%), hoarseness $(21 \%)$, wheezing $(16 \%)$, sore throat $(12 \%)$, dyspnea (10\%) and weight loss (10\%) (Table I) [25,26].

Regurgitation of undigested foods in achalasia typically occurs during meals but may also be present shortly after or up to hours later when the affected person lies down. On detailed history taking patients will report prolonged times to finish up a meal and avoidance of eating out.

Eckardt et al. proposed a scoring system for grading dysphagia, chest pain, regurgitation and weight loss, currently this score being the most commonly used for the evaluation of symptoms, staging and result of treatment in achalasia. A symptom score of 0 corresponds to clinical stage 0 , a score of 2-3 to stage I, a score of 4-6 to stage II, and a score $>6$ to stage III. Stages 0 and I indicate remission of the disease. Stages II and III represent failure of treatment and repeated treatment is to be considered (Table II) [27].

The diagnosis of achalasia is frequently delayed due to its rarity and slow progression. The mean delay between symptom onset and diagnosis has been reported to average $4-5$ years [28].

One of the main issues in the diagnostic approach to a patient with suspected esophageal achalasia is to exclude pseudoachalasia. In patients with rapidly progressing dysphagia, unintended weight loss, cachexia, family history of (esophageal) malignancy and older age, diseases other than achalasia should be suspected and excluded by endoscopy or CT scan.

Usually the first step in evaluating a patient suffering of dysphagia is upper endoscopy. In patients with dysphagia esophago-gastro-duodenoscopy (EGD) with mucosal biopsies of the esophagus should be performed to rule out eosinophilic esophagitis, reflux disease, peptic stenosis and stenosing processes (i.e. malignancy) of the esophagus and surrounding tissues (pseudoachalasia). Esophageal candidiasis in the context of preserved immune systems should direct to the suspicion of altered esophageal emptying.

Minami et al. found an esophageal dilatation described by EGD only in $41.1 \%$ of patients with known achalasia and mainly in advanced disease [29]. In a study performed by Fisichella et al in $26 \%$ only the narrowing of the esophago gastric junction (EGJ) was reported by the endoscopist [30]. Reports of lack of peristalsis, fluid pooling and difficult to pass LES are neither sensitive nor specific signs, but should draw the examiners' attention and consider further evaluations.

Upper endoscopy may suggest achalasia and rule out esophageal pathologies mimicking achalasia but further diagnostic testing is essential to confirm the diagnosis. 
Table I. Symptoms in achalasia and their frequency (Adapted from $[25,26])$.

\begin{tabular}{|l|l|}
\hline Symptom & Frequency \\
\hline Dysphagia & $79-100 \%$ \\
\hline Regurgitation & $63 \%$ \\
\hline Heartburn & $41 \%$ \\
\hline Cough & $37 \%$ \\
\hline Aspiration & $31 \%$ \\
\hline Non Cardiac Chest Pain & $22 \%$ \\
\hline Hoarseness & $21 \%$ \\
\hline Wheezing & $16 \%$ \\
\hline Epigastric Pain & $15 \%$ \\
\hline Soare Throat & $12 \%$ \\
\hline Dyspnea & $10 \%$ \\
\hline Weight Loss & $10 \%$ \\
\hline Odynophagia & $<5 \%$ \\
\hline
\end{tabular}

Table II. Items and grading of the Eckardt-Score ranging from 0 points (no symptoms) to 12 points (severe form of achalasia).

\begin{tabular}{|l|l|l|l|l|}
\hline Score & Dysphagia & Regurgitation & Retrosternal Pain & Weight loss \\
\hline 0 & None & None & None & None \\
\hline 1 & Occasional & Occasional & Occasional & $<5 \mathrm{~kg}$ \\
\hline 2 & Daily & Daily & Daily & $5-10 \mathrm{~kg}$ \\
\hline 3 & Each Meal & Each Meal & Each Meal & $<10 \mathrm{~kg}$ \\
\hline
\end{tabular}

Deviere et al. measured the thickness of the LES muscle layer and reported a greater mean thickness in achalasia patients then in a healthy control group [31]. These results could not be confirmed by other studies $[32,33]$ whereas a recent study by Krishnan confirmed them again [34]. Therefore, data is conflicting and the role of EUS in diagnosing achalasia remains unclear.

On the other hand, an advantage in the use of EUS for the evaluation of presumed achalasia is to exclude pseudoachalasia due to neoplasia of the EGJ, neoplasia of the pancreas or lymph node compression of the EGJ. In a retrospective study of 63 patients with esophageal motor dysfunction Krishnan et al. identified using EUS clinically significant lesions in $15 \%$ of cases, which changed the further management. Submucosal carcinoma not seen on standard endoscopy were detected in two cases. In three cases EUS identified a compression of the distal esophagus by a dilated and ectatic descending aorta. In one patient, an intramucosal sarcoid and in another a congenital distal esophageal muscular ring was found. An extrinsic compression by a submucosal leiomyoma at the cardia was found in another patient $[34,35]$.

In a nutshell, EUS is an important tool to exclude pseudoachalasia and should be considered as part of the evaluation for achalasia.

The typical finding of achalasia in barium esophagram is a birds-beak appearance of the EGJ and a dilated esophagus. While these findings are specific for achalasia and pseudoachalasia, a normal classic fluoroscopy is not capable to exclude this disease. Other than classic fluoroscopy timed barium swallow with imaging during the swallow and after 1, 2 and 5 minutes is a useful marker of esophageal emptying [36] and does not give information on the esophageal anatomy only. Its usefulness in the postprocedural follow-up will be discussed later in this review.

In conventional esophageal manometry, absence of peristalsis of $100 \%$ of swallows in the distal two thirds of the esophagus together with incomplete relaxation of the LES on deglutition is mandatory for establishing the diagnosis of esophageal achalasia. In addition, there may be an elevated intra-esophageal pressure [37].

In recent years, high-resolution esophageal manometry (HRM) became the gold standard to evaluate esophageal motility abnormalities [38]. The diagnosis of achalasia is made by documenting impaired relaxation of the lower esophageal sphincter by the integrated relaxation pressure over 4 seconds (IRP4s) and aperistalsis in the absence of esophageal obstruction near the LES. The Chicago Classification system divides achalasia in 3 subtypes (types I, II and III), dependent on the contraction pattern and the integrated relaxation pressure that have both potential prognostic and therapeutic distinctions (Table III) [39]. 
Table III. Subtypes of achalasia as defined by the Chicago Classification.

\begin{tabular}{|l|l|}
\hline Type I & $\begin{array}{l}\text { Elevated median IRP }(>\mathrm{ULN}), 100 \% \text { failed peristalsis (DCI }<100 \mathrm{mmHg} \mathrm{s} \mathrm{cm}), \text { premature contractions with DCI } \\
\text { values less than } 450 \mathrm{mmHg} \mathrm{s}^{*} \mathrm{~cm} \text { satisfy criteria for failed peristalsis }\end{array}$ \\
\hline Type II & $\begin{array}{l}\text { Elevated median IRP }(>\mathrm{ULN}), 100 \% \text { failed peristalsis, panesophageal pressurization with } \geq 20 \% \text { of swallows. } \\
\text { Contractions may be masked by esophageal pressurization and DCI should not be calculated }\end{array}$ \\
\hline Type III & $\begin{array}{l}\text { Elevated median IRP }(>\mathrm{ULN}), \text { no normal peristalsis, premature (spastic) contractions with DCI }>450 \mathrm{mmHg} \mathrm{s} \text { cm } \\
\text { with } \geq 20 \% \text { of swallows. May be mixed with panesophageal pressurization }\end{array}$ \\
\hline
\end{tabular}

ULN - upper limit of normal (defined according to the HRM equipment used)

At present time, a curative treatment for achalasia does not exist. Therefore treatment is directed to minimize symptoms and improve quality of life. The majority of therapeutic modalities target a reduction of the obstruction caused by the poorly relaxing lower esophageal sphincter.

The primary goal is the early diagnosis of achalasia to prevent the development of late complications such as megaesophagus, with makes esophagectomy in many cases unavoidable, and to preserve esophageal function and anatomy.

Every therapeutic option encloses its own advantages, disadvantages and risks. The choice for a treatment should be individualized and adapted to the patients' preferences after an extensive informative conversation.

Oral calcium blockers, nitrates and 5-Phosphodiesterase inhibitors cause a reduction in LES pressure but only with limited benefit for dysphagia, while side effects are common. Hence they are of minor value in the treatment of achalasia [40,41]. Oral medical treatment should be reserved for patients not able or willing to undergo invasive treatment and play virtually no role in the treatment of achalasia.

Botolinum toxin injections to the LES block the release of acetylcholine from presynaptic cholinergic nerve endings resulting in a decreased LES pressure. Just above the Z-line 25IU of botulinum toxin are injected to each quadrant. The advantage of this treatment is a lower risk of perforation, morbidity and mortality compared to pneumatic balloon dilatation or myotomy. Over $80 \%$ of patients have a clinical response by one month, but less than $60 \%$ are in remission after one year, and retreatment will become necessary [42].

Hence the use of botulinum toxin should be avoided as first line treatment and reserved for patients at high risk for more invasive treatment, as an interim option before more durable treatment or in patients not willing to undergo pneumatic dilatation or myotomy. Furthermore, the use of botulinum toxin has been proposed as diagnostic tool in patients with unclear diagnosis, in order to select patients most likely to respond to more invasive treatment [43].

The oldest and still most effective non-surgical therapy for achalasia is dilating the poorly relaxing LES. It was first introduced by Sir Thomas Williams in 1674 using a device consisting of a whale bone and a sponge [1]. In contrast to esophageal strictures, where rigid dilatators (i.e. Savary bougies) are effective stretching open the esophageal lumen, larger balloons are required in achalasia. Using balloons with a diameter of $30 \mathrm{~mm}, 35 \mathrm{~mm}$ or $40 \mathrm{~mm}$ a controlled tear of the muscle fibres of the LES is achieved. Response to pneumatic dilatation is influenced by age (more than 45 years more favorable), gender (more favorable in female patients) and subtype of achalasia (subtype II most favorable) $[44,45]$.

Katzka and Castell analyzed 25 studies on pneumatic dilatation and concluded that there is no identical method of PD regarding the type of the balloon, pressure, and duration of dilatation except between two studies only. The success rate for a single dilation session was $66 \%$ at 1 year and $59 \%$ at 2 years, $53 \%$ at 3 years, $50 \%$ at 5 years and $25 \%$ at 10 years. Efficacy could be improved by the use of a Rigiflex dilator and repeated dilations during the initial treatment period. Overall perforation rate was low - $2 \%$, of which $1 \%$ required surgery. Also if more effective for the resolution of symptoms, the use of multiple PDs led to increased perforation risk [46]. In a recent study by Lynch et al. a perforation rate of $0.37 \%$ was reported for pneumatic dilatation, comparable to unrecognized perforation during Heller myotomy in the same series [47].

Wu et al. compared repeated pneumatic dilatations (in maximum three sessions) to Heller myotomy combined with Dor fundoplication in a prospective randomized trial and found a similar treatment success with both interventions in a 2 years follow up [48]. Hence a single pneumatic dilatation has lower response rate than Heller myotomy, repeated PDs are a reasonable alternative to surgery.

In 2008 Inoue et al. presented a novel therapeutic option to treat achalasia by means of per-oral esophageal myotomy (POEM). Through a small mucosal incision in the mid-esophagus and a submucosal tunnel using a transparent cap and a dissection knife on a forward viewing endoscope, a selective myotomy of the circular muscle is performed. In 500 consecutive patients Innoue et al demonstrated an overall success rate of $91.3 \%$ after 2 months and $91 \%$ after 1 to 2 years. $19.4 \%$ complained of heartburn or regurgitation after 1 to 2 years. The complication rate was low at $3.1 \%$ [49]. Bahyani and colleagues found equal reduction of esophageal symptoms, acid exposure and integrated LES pressure comparing POEM to Heller myotomy combined 
with partial fundoplication [50].

POEM is an effective alternative to surgery when performed by skilled endoscopists. Up to the present there are no randomized controlled trials comparing POEM to pneumatic dilatation. Further studies directed at the longterm outcome of POEM are needed.

Laparoscopy myotomy is currently the surgical intervention used for the treatment of achalasia. This procedure, first published by Ernst Heller in 1913 [51] and undergoing several modifications thereafter, targets same as pneumatic dilatation and POEM on the obstruction due to LES pressure. The principle is to longitudinally cut the LES and extend the incision $6-7 \mathrm{~cm}$ above the EGJ and $3 \mathrm{~cm}$ below to also cut the sling fibers of the gastric fundus involved in forming the functional LES. The standard technique is a laparoscopic approach nowadays. To avoid post-procedural gastro-oesophageal reflux disease (GERD) Heller myotomy usually is combined with antireflux surgery. The combination leads to similar relief of dysphagia but with less GERD symptoms. In a meta-analysis Campos et al. found an overall symptom relief of $90 \%$ in patients undergoing myotomy of the LES. The incidence of postoperative GERD after Heller myotomy in combination with fundoplication was $8.8 \%$ vs. $31.5 \%$ without anti-reflux surgery. They also showed a perforation rate of $6.3 \%$ in average as the most common complication [52].

For anti-reflux surgery, a full $360^{\circ}$ Nissen fundoplication is contraindicated, as $15 \%$ of patients had post-procedural dysphagia shown in a randomized trial with long term follow up for 10 years. Patients receiving a Dor fundoplication on the other hand only complained of dysphagia in $2.8 \%$ [53]. Rawlings and colleagues compared Dor $\left(180^{\circ}\right.$ anterior fundoplasty) to Toupet $\left(270^{\circ}\right.$ partial fundoplasty) procedure combined with Heller myotomy in achalasia and found no significant differences regarding dysphagia, reflux symptoms and $\mathrm{pH}$ monitoring [54].

In patients developing end-stage mega-esophagus or sigmoid esophagus, characterized by considerable dilatation and tortuosity respectively, surgical myotomy may be the initial approach before considering esophagectomy as terminal option. Sweet et al. found a symptomatic improvement in $92 \%$ of patients with mega-esophagus following Heller myotomy. In those unresponsive to surgical myotomy esophageal resection is frequently required [55]. As esophagectomy is associated with a greater morbidity and mortality than less invasive procedures it should be reserved for patients who had no response to pneumatic dilatation or myotomy and are good candidates for surgery.

Anyhow post-esophagectomy dysphagia resulting from strictures at the anastomotic site requiring dilatation is seen in up to $50 \%$ of patients [56]. The increased awareness of the disease and recent improvements in diagnosing and treating achalasia diminished the rate of end-stage achalasia and need of total esophagectomies.
Rohof and colleagues demonstrated a correlation of achalasia subtypes and prognosis. The best results from therapy with pneumatic dilatation or myotomy were found in achalasia type II with a success rate of $96 \%$. In type I a success rate of $81 \%$ and in type III of $66 \%$ only was reported [45].

Eckardt et al. found despite a significant number of complications (i.e. reflux esophagitis and megaesophagus) no significant difference in live expectancy compared to the general population over a period of 33 years [57].

Follow up in patients with achalasia should include periodic evaluation of symptoms and nutritional status summarized in the Eckardt Score. Timed barium esophagram may suggest defective esophageal emptying before symptoms arise. Up to $30 \%$ of patients with achalasia are symptom free after pneumatic dilation, despite poor esophageal emptying in barium esophagram, and $90 \%$ of these patients will have relapse within one year [58]. Esophageal manometry after pneumatic dilatation, surgical manometry or POEM is of limited clinical value since esophageal peristalsis is not expected to be normalized and pressure measurements at the level of the LES provides no information on the opening and compliance of the LES. In addition, patients' acceptance for (repeat) esophageal manometries is rather limited [59].

Retrospective studies suggest that achalasia might be associated with a higher risk for squamous esophageal cancer compared to the general population (60). While there is insufficient supporting evidence to reach a consensus if and how often endoscopic surveillance should be performed the decision and schedule is left up to the treating physician [60]). Our approach is to offer patients upper GI endoscopies every 3 years in analogy to Barrett's esophagus surveillance in the absence of dysplasia.

\section{Conclusion}

Achalasia is a primary motility disease of the esophagus and diagnosis is unfortunately still delayed. Achalasia should be included in the differential diagnosis of patients with esophageal symptoms (regurgitation, chest pressure) and dysphagia and should be actively be queried, given that at the beginning of the disease, this symptom may be subtle. In our case we present the development from focal achalasia as an early stage to spastic achalasia (type III according to the Chicago classification).

While high-resolution esophageal manometry is the gold standard to diagnose achalasia, additional investigations are needed for consolidating the definite diagnosis of achalasia. At the moment, we have a broad therapeutic armamentarium allowing a tailoring according to the patient's preferences and readiness to accept potential complications. Finally, regular follow-up of patients with achalasia is important to prevent development of end-stage disease and diminish the risk of developing esophageal neoplasia. 


\section{References}

1. Willis T. Pharmaceutie rationali, sive diatriba de medicamentorum operationibus in humano corpore. 1674; Available from: https://play.google.com/books/reader?id=Kg49 AAAAcAAJ\&printsec $=$ frontcover\&output=reader $\& \mathrm{hl}=\mathrm{de} \& \mathrm{pg}=$ GBS.PA93

2. Hurst A F. Treatment of Achalasia of the Cardia (So-called Cardiospasm). Lancet 1927;1:618.

3. Kahrilas PJ, Kishk SM, Helm JF, Dodds WJ, Harig JM, Hogan WJ. Comparison of pseudoachalasia and achalasia. Am J Med. 1987;82:439-446.

4. Herbella FA, Aquino JL, Stefani-Nakano S, Artifon EL, Sakai P, Crema E, et al. Treatment of achalasia: lessons learned with Chagas' disease. Dis Esophagus. 2008;21:461-467.

5. Stein CM, Gelfand M, Taylor HG. Achalasia in Zimbabwean blacks. S Afr Med J. 1985;67:261-262.

6. Birgisson S, Richter JE. Achalasia in Iceland, 1952-2002: an epidemiologic study. Dig Dis Sci. 2007;52:1855-1860.

7. Sadowski DC, Ackah F, Jiang B, Svenson LW. Achalasia: incidence, prevalence and survival. A population-based study. Neurogastroenterol Motil. 2010;22:e256-e261. doi: 10.1111/j.1365-2982.2010.01511.x.

8. Ho KY, Tay HH, Kang JY. A prospective study of the clinical features, manometric findings, incidence and prevalence of achalasia in Singapore. J Gastroenterol Hepatol. 1999;14:791795.

9. Enestvedt BK, Williams JL, Sonnenberg A. Epidemiology and practice patterns of achalasia in a large multi-centre database. Aliment Pharmacol Ther. 2011;33:1209-1214.

10. Ng KY, Li KF, Lok KH, Lai L, Ng CH, Li KK, et al. Ten-year review of epidemiology, clinical features, and treatment outcome of achalasia in a regional hospital in Hong Kong. Hong Kong Med J. 2010;16:362-366.

11. Howard PJ, Maher L, Pryde A, Cameron EW, Heading RC. Five year prospective study of the incidence, clinical features, and diagnosis of achalasia in Edinburgh. Gut. 1992;33:1011-1015.

12. Arber N, Grossman A, Lurie B, Hoffman M, Rubinstein A, Lilos $\mathrm{P}$, et al. Epidemiology of achalasia in central Israel. Rarity of esophageal cancer. Dig Dis Sci. 1993;38:1920-1925.

13. Mayberry JF, Atkinson M. Variations in the prevalence of achalasia in Great Britain and Ireland: an epidemiological study based on hospital admissions. Q J Med. 1987;62:67-74.

14. Farrukh A, DeCaestecker J, Mayberry JF. An epidemiological study of achalasia among the South Asian population of Leicester, 1986-2005. Dysphagia. 2008;23:161-164.

15. Gockel I, Bohl JR, Doostkam S, Eckardt VF, Junginger T. Spectrum of histopathologic findings in patients with achalasia reflects different etiologies. J Gastroenterol Hepatol. 2006;21:727-733.

16. Ghoshal UC, Daschakraborty SB, Singh R. Pathogenesis of achalasia cardia. World J Gastroenterol. 2012;18:3050-3057.

17. Lau KW, McCaughey C, Coyle P V, Murray LJ, Johnston BT. Enhanced reactivity of peripheral blood immune cells to HSV-1 in primary achalasia. Scand J Gastroenterol. 2010;45:806-813.

18. Facco M, Brun P, Baesso I, Costantini M, Rizzetto C, Berto A, et al. T cells in the myenteric plexus of achalasia patients show a skewed TCR repertoire and react to HSV-1 antigens. Am J Gastroenterol. 2008;103:1598-1609.

19. Birgisson S, Galinski MS, Goldblum JR, Rice TW, Richter JE. Achalasia is not associated with measles or known herpes and human papilloma viruses. Dig Dis Sci. 1997;42:300-306.
20. Booy JD, Takata J, Tomlinson G, Urbach DR. The prevalence of autoimmune disease in patients with esophageal achalasia. Dis Esophagus. 2012;25:209-213.

21. Kraichely RE, Farrugia G, Pittock SJ, Castell DO, Lennon VA. Neural autoantibody profile of primary achalasia. Dig Dis Sci. 2010;55:307-311.

22. Johnston BT, Colcher A, Li Q, Gideon RM, Castell JA, Castell DO. Repetitive proximal esophageal contractions: a new manometric finding and a possible further link between Parkinson's disease and achalasia. Dysphagia. 2001;16:186-189. 23. Zárate N, Mearin F, Gil-Vernet JM, Camarasa F, Malagelada JR. Achalasia and Down's syndrome: coincidental association or something else? Am J Gastroenterol. 1999;94:1674-1677.

24. Jung KW, Yoon IJ, Kim DH, Chung JW, Choi KS, Choi KD, et al. Genetic evaluation of ALADIN gene in early-onset achalasia and alacrima patients. J Neurogastroenterol Motil. 2011;17:169-173.

25. Tsuboi K, Hoshino M, Srinivasan A, Yano F, Hinder RA, Demeester TR, et al. Insights gained from symptom evaluation of esophageal motility disorders: a review of 4,215 patients. Digestion. 2012;85:236-242.

26. Sinan H, Tatum RP, Soares RV, Martin AV, Pellegrini CA, Oelschlager BK. Prevalence of respiratory symptoms in patients with achalasia. Dis Esophagus. 2011;24:224-228.

27. Gockel I, Junginger T. The value of scoring achalasia: a comparison of current systems and the impact on treatment--the surgeon's viewpoint. Am Surg. 2007;73:327-331.

28. Eckardt VF, Köhne U, Junginger T, Westermeier T. Risk factors for diagnostic delay in achalasia. Dig Dis Sci. 1997;42:580-585. 29. Minami H, Isomoto H, Miuma S, Kobayashi Y, Yamaguchi N, Urabe S, et al. New endoscopic indicator of esophageal achalasia: “pinstripe pattern”. PLoS One. 2015 Feb 9;10(2):e0101833. doi: 10.1371/journal.pone.0101833.

30. Fisichella PM, Raz D, Palazzo F, Niponmick I, Patti MG. Clinical, radiological, and manometric profile in 145 patients with untreated achalasia. World J Surg. 2008;32:1974-1979.

31. Devière J, Dunham F, Rickaert F, Bourgeois N, Cremer M. Endoscopic ultrasonography in achalasia. Gastroenterology. 1989;96:1210-1213.

32. Ponsot P, Chaussade S, Palazzo L, Amouyal P, Gaudric M, Couturier D, et al. Endoscopic ultrasonography in achalasia. Gastroenterology. 1990 Jan;98(1):253.

33. Minami $H$, Inoue $H$, Isomoto $H$, Urabe $S$, Nakao K. Clinical application of endoscopic ultrasonography for esophageal achalasia. Dig Endosc. 2015;27 Suppl 1:11-16.

34. Krishnan K, Lin CY, Keswani R, Pandolfino JE, Kahrilas PJ, Komanduri S. Endoscopic ultrasound as an adjunctive evaluation in patients with esophageal motor disorders subtyped by highresolution manometry. Neurogastroenterol Motil. 2014;26:11721178.

35. Ziegler K, Sanft C, Friedrich M, Gregor M, Riecken EO. Endosonographic appearance of the esophagus in achalasia. Endoscopy. 1990;22:1-4.

36. Neyaz Z, Gupta M, Ghoshal UC. How to perform and interpret timed barium esophagogram. J Neurogastroenterol Motil. 2013;19:251-256.

37. Agrawal A, Hila A, Tutuian R, Castell DO. Manometry and Impedance Characteristics. Facts and myths. J Clin Gastroenterol. 2008; 42:266-270.

38. Roman S, Zerbib F, Bruley des Varannes S, Mion F. Esophageal high resolution manometry: a new gold standard for the detection of transient lower esophageal sphincter relaxations? 
Neurogastroenterol Motil. 2012;24:498-9; author reply 500. 39. Kahrilas PJ, Bredenoord AJ, Fox M, Gyawali CP, Roman S, Smout AJ, et al. The Chicago Classification of esophageal motility disorders, v3.0. Neurogastroenterol Motil. 2015;27:160-174.

40. Gelfond M, Rozen P, Gilat T. Isosorbide dinitrate and nifedipine treatment of achalasia: a clinical, manometric and radionuclide evaluation. Gastroenterology. 1982;83:963-969.

41. Bortolotti M, Mari C, Lopilato C, Porrazzo G, Miglioli M. Effects of sildenafil on esophageal motility of patients with idiopathic achalasia. Gastroenterology. 2000;118:253-257.

42. Leyden JE, Moss AC, MacMathuna P. Endoscopic pneumatic dilation versus botulinum toxin injection in the management of primary achalasia. Cochrane Database Syst Rev. 2014;(12):CD005046. doi: 10.1002/14651858.CD005046.pub3.

43. Katzka DA, Castell DO. Use of botulinum toxin as a diagnostic/ therapeutic trial to help clarify an indication for definitive therapy in patients with achalasia. Am J Gastroenterol. 1999;94:637-642. 44. Farhoomand K, Connor JT, Richter JE, Achkar E, Vaezi MF. Predictors of outcome of pneumatic dilation in achalasia. Clin Gastroenterol Hepatol. 2004;2:389-394.

45. Rohof WO, Salvador R, Annese V, Bruley des Varannes S, Chaussade S, Costantini M, et al. Outcomes of treatment for achalasia depend on manometric subtype. Gastroenterology. 2013;144:718-725.

46. Katzka DA, Castell DO. Review article: an analysis of the efficacy, perforation rates and methods used in pneumatic dilation for achalasia. Aliment Pharmacol Ther. 2011;34:832-839.

47. Lynch KL, Pandolfino JE, Howden CW, Kahrilas PJ. Major complications of pneumatic dilation and Heller myotomy for achalasia: single-center experience and systematic review of the literature. Am J Gastroenterol. 2012;107:1817-1825.

48. Wu JCY. Pneumatic dilation versus laparoscopic Heller's myotomy for idiopathic achalasia. J. Neurogastroenterol. Motil. 2011; 17:324-326.

49. Inoue H, Sato H, Ikeda H, Onimaru M, Sato C, Minami H, et al. Per-Oral Endoscopic Myotomy: A Series of 500 Patients. J Am Coll Surg. 2015;221:256-264.

50. Bhayani NH, Kurian AA, Dunst CM, Sharata AM, Rieder

E, Swanstrom LL. A comparative study on comprehensive, objective outcomes of laparoscopic Heller myotomy with peroral endoscopic myotomy (POEM) for achalasia. Ann Surg. 2014;259:1098-1103.

51. Heller E. Extra mucous cardioplasty in chronic cardiospasm with dilatation of the esophagus (Extramukose Cardiaplastik mit Dilatation des Oesophagus). Mitt Grenzgels Med Chir. 1913;27:141-148.

52. Campos GM, Vittinghoff E, Rabl C, Takata M, Gadenstätter $\mathrm{M}$, Lin F, et al. Endoscopic and surgical treatments for achalasia: a systematic review and meta-analysis. Ann Surg. 2009;249:45-57. 53. Rebecchi F, Giaccone C, Farinella E, Campaci R, Morino M. Randomized controlled trial of laparoscopic Heller myotomy plus Dor fundoplication versus Nissen fundoplication for achalasia: long-term results. Ann Surg. 2008;248:1023-1030.

54. Rawlings A, Soper NJ, Oelschlager B, Swanstrom L, Matthews BD, Pellegrini C, et al. Laparoscopic Dor versus Toupet fundoplication following Heller myotomy for achalasia: results of a multicenter, prospective, randomized-controlled trial. Surg Endosc. 2012;26:18-26.

55. Sweet MP, Nipomnick I, Gasper WJ, Bagatelos K, Ostroff JW, Fisichella PM, et al. The outcome of laparoscopic Heller myotomy for achalasia is not influenced by the degree of esophageal dilatation. J Gastrointest Surg. 2008;12:159-165.

56. Molena D, Yang SC. Surgical management of end-stage achalasia. Semin Thorac Cardiovasc Surg. 2012;24:19-26.

57. Eckardt VF, Hoischen T, Bernhard G. Life expectancy, complications, and causes of death in patients with achalasia: results of a 33-year follow-up investigation. Eur J Gastroenterol Hepatol. 2008;20:956-960.

58. Vaezi MF, Baker ME, Achkar E, Richter JE. Timed barium oesophagram: better predictor of long term success after pneumatic dilation in achalasia than symptom assessment. Gut. 2002;50:765-770.

59. Vaezi MF, Pandolfino JE, Vela MF. ACG clinical guideline: diagnosis and management of achalasia. Am J Gastroenterol. 2013; 108:1238-1249.

60. Ravi K, Geno DM, Katzka DA. Esophageal cancer screening in achalasia: is there a consensus? Dis Esophagus. 2014;28(3):299304. 